\title{
Clinical and Demographic Predictors of Mortality due to COVID-19 Pandemic: A Retrospective Study
}

\author{
Ayushi Rajkumar Jain ${ }^{a}$, Doss Prakash ${ }^{b}$, Sheetal Swamy ${ }^{c}$, Sanskruti Tahakik \\ ${ }^{a}$ Masters in Physiotherapy Resident, MGM Institute of Physiotherapy, Aurangabad, Maharashtra, India \\ ${ }^{\mathrm{b}}$ Associate Professor, MGM Institute of Physiotherapy, Aurangabad, Maharashtra, India \\ ${ }^{\mathrm{c}, \mathrm{d}}$ Assistant Professor, MGM Institute of Physiotherapy, Aurangabad, Maharashtra, India
}

Corresponding Author: Ayushi Rajkumar Jain

\begin{abstract}
The alarming statistics of COVID-19 surges up in 2021 throwing an enormous burden on the healthcare system across the world. According to WHO reports on $14^{\text {th }}$ April 2021, globally 136,996,364 confirmed COVID-19 cases are reported across the continents, including 2,951,832 deaths. The state of Maharashtra reported the maximum number of cases of India including high mortality rate. This study was conducted to identify and describe the relation of different predictors (Age, gender, duration of hospital stay, presence of co morbidities) of mortality among the COVID-19 deceased patients by retrospectively analyzing the medical case records of 121 patients from a dedicated COVID hospital at Aurangabad from July 2020 to December 2020. Chi-square test was performed to assess the association between causes of death with different cluster of variables and their significance. This study helps us to identify risk factors that show association between various predictors and mortality rate in COVID-19 patients. Out of 121 deaths, 96 (79\%) were male, 61 (49.6\%) were in age group between 60-79 years, ARDS was one of the major complication in the deceased patients accounting $29.8 \%$ and cardio respiratory arrest was the common cause of death among the deceased patients with $85 \%$. It was also observed that mortality rate was very higher in the initial five days of hospitalization with critical care support. Our result findings provide clinical inferences for physicians to identify high-risk factors with COVID-19 at a very early stage.
\end{abstract}

Key Words- COVID-19, Mortality rate, Demographic predictors, Co-morbidities, Cardio respiratory arrest.

\section{INTRODUCTION}

The novel Corona virus (SARSCoV-2) outbreak created a destructive impact on day to day life and stressed the health care systems across the world including India. ${ }^{[1]}$ The alarming statistics of COVID-19 surges up in 2021 throwing an enormous burden on the healthcare system across the world. According to WHO reports on $14^{\text {th }}$ April 2021, globally 136,996,364 confirmed COVID-19 cases are reported across the continents, including 2,951,832 deaths. Individuals with COVID19 present with influenza like symptoms and respiratory tract infection with clinical representation of fever (89\%), cough (68\%), fatigue (38\%), sputum production (34\%) and/or shortness of breath (19\%). The main clinical symptoms of COVID-19 are generally associated with upper respiratory tract infections and high viral loads in upper respiratory tract secretions. This may evolve and progress towards Severe Acute Respiratory Infection (SARI). The spectrum of disease severity ranges from an asymptomatic infection, mild upper respiratory tract illness, and severe viral pneumonia with respiratory failure and/or death. Current reports estimate that $80 \%$ of cases are asymptomatic or mild; $15 \%$ of 
cases are severe (infection requiring oxygen); and $5 \%$ are critical requiring ventilation and life support. ${ }^{[2]}$ With the rising prevalence of cardio metabolic disorders globally, individuals with Diabetes Mellitus, Hypertension and such conditions can highly influence their health status in a dreadful way. ${ }^{[3]}$ In some cases like elderly, patients with co morbidities and immune suppression, it may progress to acute respiratory distress syndrome (ARDS). ${ }^{[4]}$

The possible reason behind lower mortality figures in India when compared to other countries is unclear. India's recovery rate from COVID-19 is higher than those of several other countries with similar COVID19 infection rates. This can be possibly due to many of reasons including more testing rates, timely detection, and treatment. [5] There is an existing evidence that social factors, such as perceived sociability, socioeconomic disadvantage, health literacy, trust in regulatory authorities, and the velocity of measures instituted to control the extend of COVID-19 can critically influence the living. ${ }^{[6,7]}$ An unexpected observation in the context of this pandemic has been the extensive variations in prevalence, mortality rate, and case fatality rate across affected countries, which cannot be completely explained on the basis of differences in the virulence of SARS-CoV-2 strains. While some of this variation may reflect differences in health care and testing capacity across nations. Besides the demographic and socioeconomic variables discussed above, an important factor that may influence such variations in the Indian context is the availability and quality of health care. Health care facilities in India are unevenly distributed, with a significant urban-rural divide, and this inequality is further exacerbated by the COVID-19 pandemic. ${ }^{[\mathbf{8}, 9]}$ Currently, the epidemiologic evidence indicates that mortality of individuals with COVID-19 is affected differently between genders with different age. Hence, it remains important to examine the role of other factors in causing this variability, particularly co morbidities, demographic determinants of health. Some Indian states like Maharashtra and Tamil Nadu reported maximum number of infected cases and possessed a high mortality of SARS CoV- 2 infected patients. [10] To effectively prioritize rationale for patients with the highest risk, we identified clinical predictors of patients who suffered and were deceased due to the cause from having mild symptoms or more. This study was undertaken to correlate different factors including demographics and major comorbidities leading to death of individuals.

\section{METHODS}

A retrospective study was conducted in a single COVID care centre treating patients infected with corona virus who are admitted for regular care and critical care. The COVID care centre patient's database was assessed retrospectively from $01^{\text {st }}$ of July 2020 to $31^{\text {st }}$ December 2020 for a period of six months. Informed consent was obtained by all the patients and their close relatives at the time of admission to COVID-19 care with the permission to utilize their clinical data for any kind of research study with their privacy rights protected. The ethical approval from the institutional ethical committee was also received. The deceased patient's database and medical records were retrieved for further analysis. According to the database present in the literature which is suggestive of many causes leading to the death, several studies have noted cardiac arrhythmias, cardiomyopathy, and cardiac arrest as terminal events in patients with COVID-19. [11] Many social factors interact with an individual's psychological responses to influence behavior either positively or negatively. ${ }^{[12]}$ The following correlations were estimated with relationship of age with mortality, influence of gender on mortality, systemic involvement leading to death, relation between hospital stay and death. 


\section{Statistical analysis}

Descriptive statistics such as mean, Standard deviation (SD) and percentage was used to present the data. Chi-square test to assess the association between causes of death with different cluster of variables such as age, gender, number of days of hospitalization and co- morbidities was used. A p-value less than 0.05 were considered as significant. Data analysis was performed using software SPSS v20.0

\section{RESULTS}

The mortality age groups due to COVID-19 were grouped in five categories ranging from age of below 20, 20-39, 40$59,60-79$ and above 80 year. The mortality rate in age groups are represented in form of graph - 1

The mortality rate was higher in age group between 60 to 79 years comprising of $49.6 \%$ and mortality rate was very much lesser in young age population.

The gender wise COVID 19 mortality rates are represented in graph 2 . The previous study by Cheng and colleagues, [13] concluded that mortality rates are lower in female population. Our study results also conclude with the significant finding of women lesser mortality rate of $20.7 \%$ ( 25 females) where as the mortality rate in men is of $79.3 \%$ (96 males)

The COVID-19 mortality rate was very much higher in patients with co-morbid medical conditions. The most common comorbidities leading to death are unspecified respiratory related conditions, acute kidney injury(AKI), acute respiratory distress syndrome(ARDS), chronic kidney disease (CKD), diabetes mellitus (DM), hypertension (HTN), multi organ dysfunction, pneumonia, sepsis and others. The mortality rate and co-morbidities data are represented in graph 3. Majority of the deceased COVID-19 patients were due to
Acute Respiratory Distress Syndrome (ARDS)

The length of the hospital stay and mortality rate was represented in graph 4 . The length of hospital stay is categorized in four groups - less than 5 days, 5-9 days, 1014 days, more than 14 days. The mortality rate is higher in the initial 5 days of hospital stay with $38 \%$ mortality rate.

This retrospective study was conducted by analyzing the medical record case files of the deceased COVID-19 patients. The three major causes of death acute respiratory failure, cardio respiratory arrest and sepsis with septic shock are represented graphically in graph 5 .

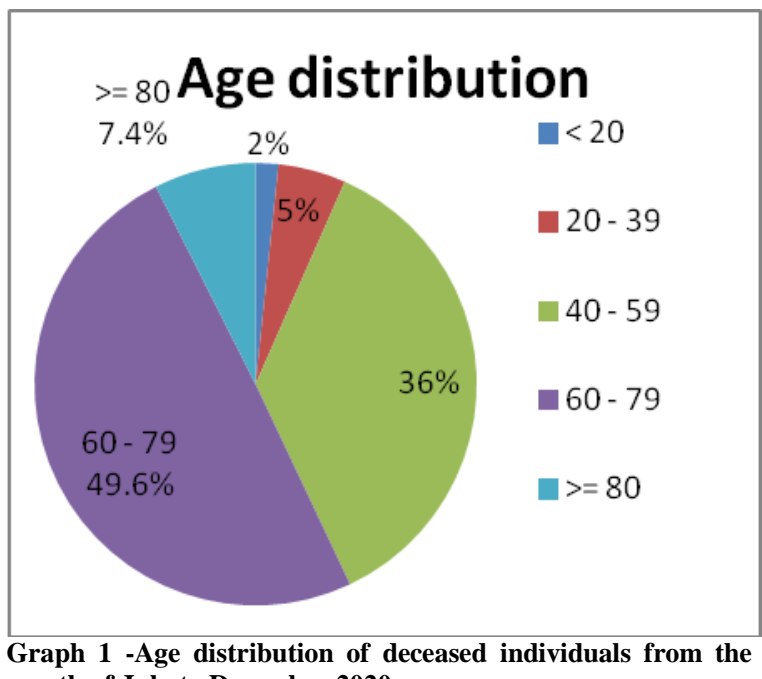
month of July to December 2020

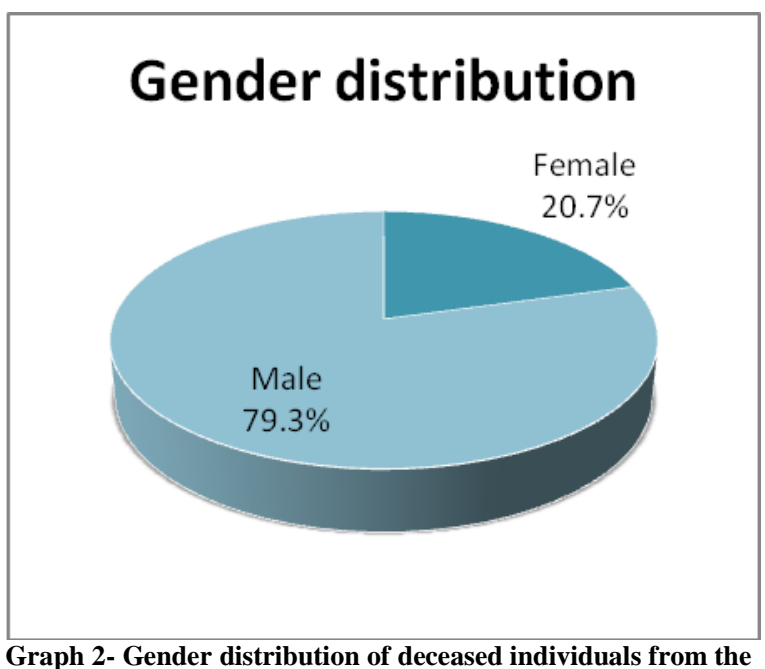

month of July to December 2020 
Ayushi Rajkumar Jain et.al. Clinical and demographic predictors of mortality due to COVID-19 pandemic: a retrospective study.

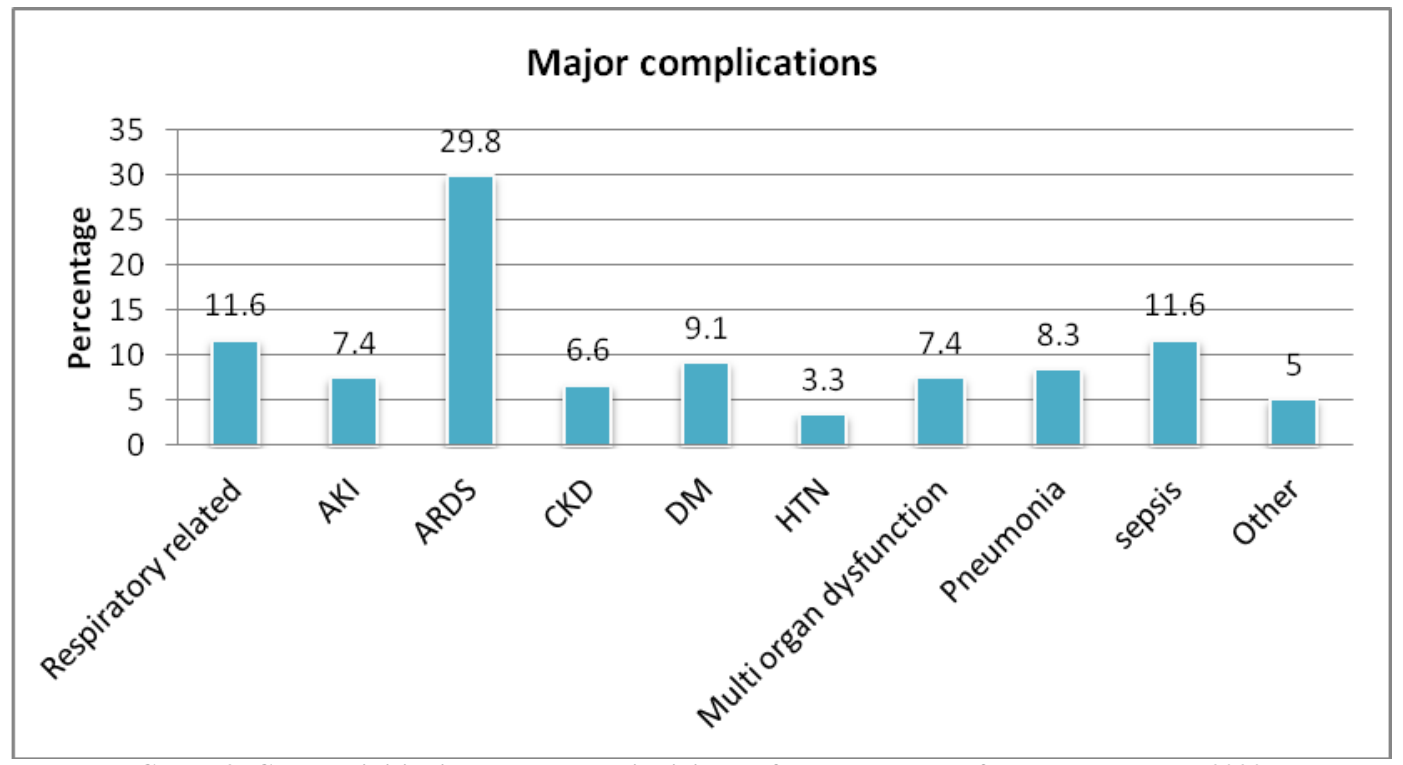

Graph 3- Co-morbidities in the deceased individuals from the month of July to December 2020

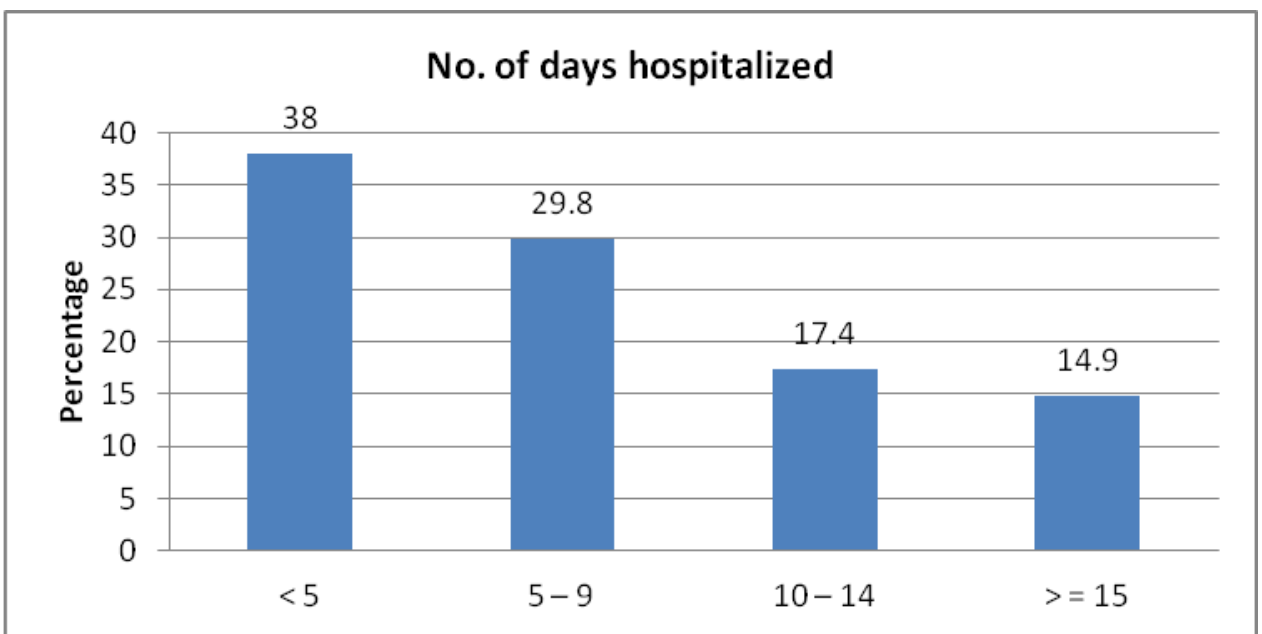

Graph 4- Hospital stay \& deceased individuals data from the month of July to December 2020

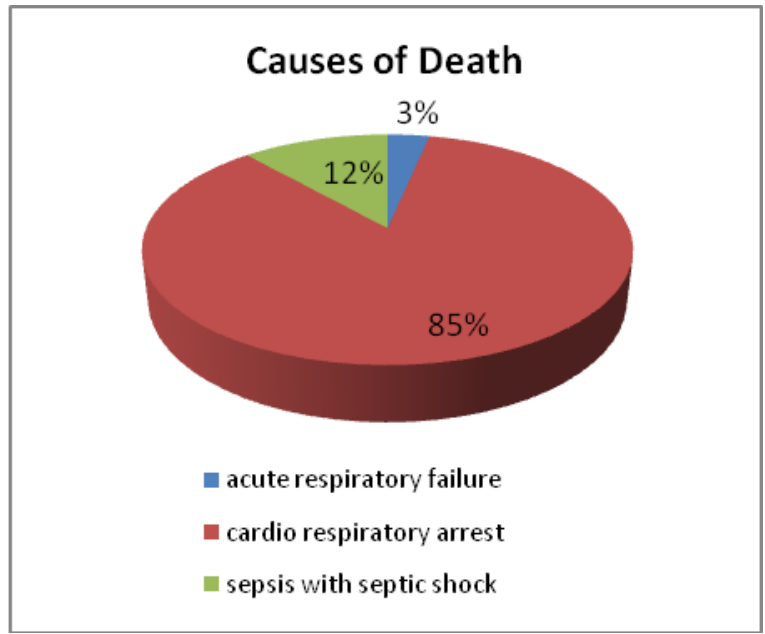

Graph 5-Major cause of death from July to December 2020 in all the individuals

Cardio respiratory arrest was the most common cause of death in the age group of 40-79 years as shown in table 1, however, there was no significant association was found between cause of death and age $(\mathrm{p}=0.96)$ Male population are more prone to death due to cardio respiratory arrest, however, there was no significant association was found between cause of death and gender $(\mathrm{p}=0.53)$ Less than 5 days of hospital stay was found to have more deaths due to cardio respiratory arrest, however, there was no significant association was found between cause of death and number of hospital days $(\mathrm{p}=0.92)$ Most common major complication was ARDS, which has more deaths due to cardio respiratory arrest, however, there was no significant association was found between cause of death and gender $(\mathrm{p}=0.87)$ 
Ayushi Rajkumar Jain et.al. Clinical and demographic predictors of mortality due to COVID 19 pandemic: a retrospective study.

Table 1 - Correlation of age, gender, number of days hospitalized and major complications with the cause of death

\begin{tabular}{|c|c|c|c|c|c|}
\hline 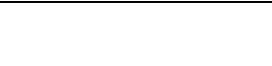 & $\begin{array}{ll}\text { acute } & \text { respiratory } \\
\text { failure } & \end{array}$ & $\begin{array}{ll}\text { cardio } & \text { respiratory } \\
\text { arrest } & \end{array}$ & $\begin{array}{l}\text { sepsis with septic } \\
\text { shock }\end{array}$ & $\chi^{2}-$ Value & p-value \\
\hline \multicolumn{6}{|l|}{ Age group } \\
\hline$<20$ & 0 & 2 & 0 & \multirow{5}{*}{0.083} & \multirow{5}{*}{0.96} \\
\hline $20-39$ & 1 & 5 & 0 & & \\
\hline $40-59$ & 1 & 37 & 6 & & \\
\hline $60-79$ & 2 & 53 & 5 & & \\
\hline$>=80$ & 0 & 6 & 3 & & \\
\hline \multicolumn{6}{|l|}{ Gender } \\
\hline Female & 0 & 23 & 2 & \multirow{2}{*}{0.39} & \multirow{2}{*}{0.53} \\
\hline Male & 4 & 80 & 12 & & \\
\hline \multicolumn{6}{|l|}{$\begin{array}{lcc}\begin{array}{l}\text { No. of } \\
\text { hospitalized }\end{array} & \text { Days } \\
\end{array}$} \\
\hline$<5$ & 1 & 40 & 5 & \multirow{4}{*}{0.91} & \multirow{4}{*}{0.92} \\
\hline $5-9$ & 2 & 30 & 4 & & \\
\hline $10-14$ & 0 & 17 & 4 & & \\
\hline$>=15$ & 1 & 16 & 1 & & \\
\hline \multicolumn{6}{|l|}{ Major complications } \\
\hline Respiratory related & 1 & 12 & 1 & \multirow{10}{*}{2.47} & \multirow{10}{*}{0.87} \\
\hline AKI & 0 & 6 & 3 & & \\
\hline ARDS & 0 & 31 & 5 & & \\
\hline CKD & 1 & 7 & 0 & & \\
\hline $\mathrm{DM}$ & 0 & 10 & 1 & & \\
\hline HTN & 0 & 4 & 0 & & \\
\hline $\begin{array}{ll}\text { Multi } \\
\text { dysfunction }\end{array}$ & 0 & 6 & 3 & & \\
\hline Pneumonia & 1 & 9 & 0 & & \\
\hline Sepsis & 1 & 12 & 1 & & \\
\hline Other & 0 & 6 & 0 & & \\
\hline
\end{tabular}

\section{DISCUSSION}

The principle finding of this analysis established the correlation of different factors either clinical of demographical which led to the mortality in COVID-19 individuals. The mortality rate in COVID 19 patients was associated with age and it is one of the primary factors. It was very much evident that the elderly population is severely affected from COVID-19 and death rates are very much higher in this geriatric age group. ${ }^{[14,15]}$ The results of this present study also confirm that more deceased patients from COVID-19 are from geriatric age group. In a retrospective study conducted by Ruan et al., there was a significant difference in age between death group and discharge group. In their study, mortality increased with an increase in age. ${ }^{[16]}$ Another study by Zhou et al., analyzed data of 191 laboratory confirmed COVID 19 cases and documented that older age was associated with increased odds of death (OR 1.13; $\mathrm{p}=0.0043)$. ${ }^{[17]}$ The grounds of age dependent decline in cell mediated immunity and humoral immunity with a Th2 skewed response which may be a responsible factor for increased mortality in elderly. ${ }^{[18]}$ The findings were also similar to the study done by Gupta et al. ${ }^{[19]}$ which reported higher COVID positivity in the age group of 40-69 years compared to others. The reason could be due to the increase in likelihood of having co morbidities with increasing age which are known risk factors for COVID-19 infection and prognosis. $[20,21]$

Gender was also another demographic factor influencing the mortality rate in COVID-19 patients. The present study result reveals, the mortality rate is more in male gender with $79.3 \%$ among the deceased COVID-19 patients over a period of six months in this COVID care centre.

Many previous studies support our study regarding the disproportionate mortality rate in the male gender which is unclear. But it was noted that deficiency of ensuring proper hand hygiene may be a causative factor for increased prevalence of COVID-19 infection in males. Social roles of females in Asian countries like India such as cooking, house cleaning etc may sensitize females to have a different perspective towards hand hygiene. Higher rates of 
tobacco consumption, increased concentration of Angiotensin converting enzyme 2 (ACE-2) in males as compared to females can be also another reason for increased COVID-19 prevalence and mortality rates in male population. ${ }^{[22]}$ Many clinical case series also report the predominance of male patients in hospitalized samples, as well as a link between male sex and mortality due to COVID-19. ${ }^{[23-26]}$ A study also concluded that the death rate by COVID-19 is lower in women than in men. ${ }^{[27]}$ A study by Zhou et al, conflicted with our results as they found that there was no significant effect of gender on mortality due to COVID-19. ${ }^{[17]}$

Pre-existing co morbidities in COVID-19 patients have poor prognosis and their medical condition deteriorate faster. In a meta analysis by Yang et al, patients with any of the co-morbidities like hypertension, diabetes mellitus, cardiovascular disease, chronic respiratory disease and cancer in their reported dataset had 10.3 times higher odds of death due to COVID-19 as compared to those without any co-morbidity. [28] In another metaanalysis by $\mathrm{Li}$ et al., with incorporating six studies with 1527 patients, co-morbidities like hypertension, cardio-cerebro vascular diseases, and diabetes were more common in severe patients. ${ }^{[29]}$ One more supporting similar retrospective single center case series, observed that patients with underlying cardiovascular diseases and other co-morbidities had higher incidence of myocardial injury and such patients developed myocardial injury had higher mortality. ${ }^{[30]}$ A study conducted by Neeraj and his colleague in Bihar state of India observed that those who required ICU at admission were at more risk of mortality. The root cause could be due to the relative higher severity of the disease, poor prognosis of study participants. Considering COVID status, those who were COVID positive with co morbidities had 6.3 times higher odds of mortality compared to others. ${ }^{[27]}$ In a Meta analysis by Ashish Kumar and his colleagues established that existence of underlying diabetes in patients with COVID-19 is associated with two-fold increased risk of mortality, as well as twofold increased risk of severity of COVID19. Another reason being ischemic heart disease is commonly associated with other medical conditions, such as systemic hypertension and chronic renal disease, which themselves deteriorate the outcomes of COVID-19, and COVID-19 has been documented to trigger myocardial injury in patients with pre-existing coronary artery disease. ${ }^{[31]}$ Predictors of a fatal outcome in COVID- 19 cases as mentioned above included the presence of underlying diseases, the presence of secondary infection and elevated inflammatory indicators in the blood suggesting that COVID-19 mortality might be due to virusactivated "cytokine storm syndrome" or fulminant myocarditis. ${ }^{[16]}$

\section{CONCLUSION}

The pattern of infection and mortality rates varied significantly amongst different countries. Surprisingly, high income countries with advanced and sophisticated healthcare resources have been more affected by this pandemic and have seen higher mortality rates, compared to low-middle income countries like India and other Southeast Asian nations leading to conclude different predictors. ${ }^{[5]}$ Our study concluded that cardio respiratory arrest was noted as the terminal event of death along with sepsis and acute respiratory failure in deceased COVID 19 patients. However, this study found that males were more prone to the death and age of adults ranging from sixty to seventy nine were also found to be more affected but these variables aren't the alone factors contributing an additional effect on the cause of death. Presence of co morbidities was found to be the other attributes affecting mortality. Also, this study found that mortality rate was very higher in the initial five days of hospitalization with critical care support. Due to the complex interaction between comorbid factors and mortality the results tend 
to be variable. Future studies of longer duration and multicentre can be conducted for significantly conclusive results. Also we suggest that in view of various levels of lockdowns being implemented across the world, that even when the lockdowns are eased, the senior citizens and those individuals with co-morbidities need to be protected from getting exposed and highquality care should be provided in the first crucial days of admission to the hospital.

\section{Acknowledgement}

I would like to thank the entire hospital team for the support they have provided. I am grateful to my entire team for helpful advice and critical discussions on the study design and the manuscript. We would like to thank our statistician for the technical support.

\section{Conflicts of interest}

We wish to confirm that there are no known conflicts of interest associated with this publication and there has been no financial support for this work.

\section{Abbreviations -}

AKI- Acute Kidney Injury, ARDSAcute Respiratory Distress Syndrome, DMDiabetes Mellitus, HTN- Hypertension, SARI- Severe Acute Respiratory Illness, SD- Standard Deviation, WHO- World Health Organization.

\section{Source of Funding: None}

\section{Ethical Approval: Approved}

\section{REFERENCES}

1. Iyengar KP, Ish P, Upadhyaya GK et al. COVID-19 and mortality in doctors. Diabetes \& Metabolic Syndrome: Clinical Research \& Reviews. 2020 Nov 1;14(6): 1743-6.

2. World Health Organization . 2020. Coronavirus disease 2019 (COVID-19) Situation Report 46.

3. Mathew T, John SK, Sarma GR et al. COVID-19-related strokes are associated with increased mortality and morbidity: A multicenter comparative study from Bengaluru, South India. International Journal of Stroke. 2020 Oct 9:1747493020968236.

4. Guan WJ, Ni ZY, Hu Y et al Clinical Characteristics of Coronavirus Disease 2019 in China. New England Journal of Medicine. 2020 Apr 30;382(18):1708-20

5. Jain VK, Iyengar $K$, Vaish $A$ et al. Differential mortality in COVID-19 patients from India and western countries. Diabetes \& Metabolic Syndrome: Clinical Research \& Reviews. 2020 Sep 1;14(5):1037-41.

6. Al-Tawfiq JA, Leonardi R, Fasoli G, Rigamonti D. Prevalence and fatality rates of COVID19: What are the reasons for the wide variations worldwide? Travel Medicine and Infectious Disease 2020 May;35:101711

7. Khalatbari Soltani S, Cumming RG, Delpierre $\mathrm{C}$ et al. Importance of collecting data on socioeconomic determinants from the early stage of the COVID-19 outbreak onwards. J Epidemiol Community Health 2020 Aug 1;74(8):620-623

8. Goel S, Angeli F, Bhatnagar $\mathrm{N}$ et al. Retaining health workforce in rural and underserved areas of India: What works and what doesn't? A critical interpretative synthesis. The National Medical Journal of India 2016 July 1;29(4):212-218

9. Andrade C. COVID-19: humanitarian and health care crisis in a third world country. The Journal of Clinical Psychiatry 2020 April 14;81(3):0-3

10. Padhi S, Suvankar S, Panda VK et al. Lower levels of vitamin D are associated with SARS-CoV-2 infection and mortality in the Indian population: An observational study. International immunopharmacology. 2020 Nov 1;88:107001.

11. Mehra MR, Desai SS, Kuy $\mathrm{S}$ et al. Cardiovascular disease, drug therapy, and mortality in Covid-19. New England Journal of Medicine. 2020 Jun 18;382(25):e102.

12. Rajkumar RP. The Relationship between Demographic, Socioeconomic, and HealthRelated Parameters and the Impact of COVID-19 on 24 Regions in India: Exploratory Cross-Sectional Study. JMIR public health and surveillance. 2020;6(4): e23083

13. Cheng H, Wang Y, Wang GQ. Organprotective effect of angiotensin converting enzyme 2 and its effect on the prognosis of 
COVID-19. Journal of Medical Virology 2020 July;92(7):726-30

14. Li $\mathrm{H}$, Wang $\mathrm{S}$, Zhong $\mathrm{F}$, et al. Agedependent risks of incidence and mortality of COVID-19 in Hubei Province and other parts of China. Frontiers in Medicine. 2020 April 30;7:190.

15. Docherty AB, Harrison EM, Green CA, et al. Features of 20133 UK patients in hospital with covid-19 using the ISARIC WHO Clinical Characterisation Protocol: prospective observational cohort study. BMJ 2020 May 22;369:1985.

16. Ruan Q, Yang K, Wang W, et al. Clinical predictors of mortality due to COVID-19 based on an analysis of data of 150 patients from Wuhan, China. Intensive Care Medicine. 2020 May;46(5): 846-848

17. Zhou F, Yu T, Du R, et al. Clinical course and risk factors for mortality of adult in patients with COVID-19 in Wuhan, China: a retrospective cohort study. The Lancet 2020 Mar 28;395(10229): 1054-1062.

18. Opal SM, Girard TD, Ely EW. The immunepathogenesis of sepsis in elderly patients. Clinical Infectious Diseases 2005 Nov 15;41(Supplement_7): S504-12.

19. Gupta N, Praharaj I, Bhatnagar T, et al. Severe acute respiratory illness surveillance for coronavirus disease 2019, India, 2020. The Indian Journal of Medical Research 2020 Feb;151:236-40.

20. Fang L, Karakiulakis G, Roth M. Are patients with hypertension and diabetes mellitus at increased risk for COVID-19 infection? The Lancet. Respiratory Medicine 2020 April;8(4):e21.

21. Marhl M, Grubelnik V, Magdič M, et al. Diabetes and metabolic syndrome as risk factors for COVID-19. Diabetes and Metabolic Syndrome 2020 July 1;14(4):6717.

22. The New York Times. Why are so many more men dying from coronavirus? Available at: https://www.nytimes.com/2020/04/02/opini on/coronavirusmen-women.

23. Yu C, Lei Q, Li W, et al. Clinical Characteristics, Associated Factors, and Predicting COVID-19 Mortality Risk: A Retrospective Study in Wuhan, China. American Journal of Preventive Medicine 2020 Aug;59(2):168-175
24. Saluja M, Pillai D, Jeliua S, et al. COVID 19 - Clinical Profile, Radiological Presentation, Prognostic Predictors, Complications And Outcome: A Perspective From The Indian Subcontinent. J Assoc Physicians India 2020 July 1;68(7):13-18

25. Mikami T, Miyashita H, Yamada T, et al. Risk Factors for Mortality in Patients with COVID-19 in New York City. Journal of General Internal Medicine. 2021 Jan;36(1): 17-26.

26. Shahriarirad R, Khodamoradi Z, Erfani A, et al. Epidemiological and clinical features of 2019 novel coronavirus diseases (COVID-19) in the South of Iran. BMC Infectious Diseases 2020 Dec;20(1):1-2

27. Agarwal N, Biswas B, Lohani P. Epidemiological determinants of COVID-19 infection and mortality: A study among patients presenting with severe acute respiratory illness during the pandemic in Bihar, India. Nigerian Postgraduate Medical Journal. 2020 Oct 1;27(4):293

28. Yang J, Zheng Y, Gou X, et al. Prevalence of comorbidities in the novel Wuhan coronavirus (COVID-19) infection: a systematic review and meta-analysis. International Journal of Infectious Diseases 2020 March 12;10.

29. Li B, Yang J, Zhao F, et al. Prevalence and impact of cardiovascular metabolic diseases on COVID-19 in China. Clinical Research Cardiology 2020 May;109(5):531-8

30. Guo T, Fan $Y$, Chen M, et al. Cardiovascular implications of fatal outcomes of patients with coronavirus disease 2019 (COVID-19). JAMA Cardiology 2020 July 1;5(7):811-818

31. Iaccarino G, Grassi G, Borghi C, et al. Age and multimorbidity predict death among COVID-19 patients: results of the SARSRAS study of Italian Society of Hypertension. Hypertension. 2020 Aug; 76(2):366-372.

How to cite this article: Jain AR, Prakash D, Swamy $\mathrm{S}$ et.al. Clinical and demographic predictors of mortality due to COVID-19 pandemic: a retrospective study. Int J Health Sci Res. 2021; 11(5): 74-81. DOI: https://doi.org/ 10.52403/ijhsr.20210511 